\title{
Menores em conflito com a lei em Moçambique: reflexões sobre medidas socioeducativas e limites para sua aplicação prática
}

\section{Children in conflict with the law in Mozambique: reflections on educational measures and limits for their practical application}

\author{
Tomás Xavier Francisco* \\ Solange Moraes Barros ${ }^{* *}$
}

\begin{abstract}
Resumo: Este artigo tem por fim analisar, por um lado, a problemática dos menores ${ }^{1}$ em conflito com a lei em Moçambique, e por outro lado, fazer reflexões sobre as medidas socioeducativas e limites para a sua aplicação prática. O trabalho contempla uma introdução, desenvolvimento no qual arrola-se considerações sobre o histórico da legislação sobre criança ou menores no país, reflexões sobre medidas socioeducativas e seus limites para sua aplicação prática e, por fim, contempla considerações finais e referências bibliográficas. A metodologia usada foi estudo exploratório, recorrendo-se a pesquisa bibliográfica e análise documental.
\end{abstract}

Palavras-chave: Moçambique. Menores em conflito com a lei. Medidas socioeducativas e limites para sua aplicação prática.

\begin{abstract}
This article aims to examine, first, the issue of minors in conflict with the law in Mozambique, and moreover, do reflections on educational measures and limits to its practical application. The work includes an introduction, which enrolls development considerations regarding the history of legislation on child or children in the country, reflections on educational measures and limits to its practical application, and finally, offers concluding remarks and references. The methodology was exploratory, using up the literature and document analysis.
\end{abstract}

Keyword: Mozambique. Minors in conflict with the law. Educational measures and limits its practical application.

Recebido em: 11/11/2011. Aceito em: 20/11/2012.

\footnotetext{
* Possui graduação em Ciências Policiais pela Academia de Ciências Policiais e mestrado em Ciências Sociais Aplicadas pela Universidade Estadual de Ponta Grossa- Paraná/Brasil. Atualmente é responsável pela área de formação, na Direção de Pessoal e Formação do Comando Provincial da Polícia da República de Moçambique (PRM) de Tete e um dos monitores dos estudos de aprimoramento e superação técnica policial e científica ao nível do mesmo comando. E-mail: tomasxavier.j@gmail.com

** Possui graduação em Serviço Social pela Universidade Estadual de Ponta Grossa, especialização em Antropologia Social pela Universidade Federal do Paraná, mestrado em Serviço Social pela Pontifícia Universidade Católica de São Paulo e doutorado em Serviço Social pela Pontifícia Universidade Católica de São Paulo. Professora Associada C da Universidade Estadual de Ponta Grossa. Coordenadora do Núcleo de Estudos Pesquisa e Assessoria na Área da Infância/Adolescência e Juventude. E-mail: solangebarros@brturbo.com.br

${ }^{1}$ Neste estudo adotamos o termo menor, o termo que a legislação moçambicana sobre criança adota para designar os indivíduos com a idade abaixo dos 18 anos. Importa referir que em Moçambique o termo "menor" não é pejorativo e muito menos discriminatório, como acontece na realidade brasileira.
} 


\section{Introdução}

Falar de menores em conflito com a lei hoje em Moçambique é falar de um tema que preocupa a todos, desde os organismos estatais de administração de justiça até aqueles organismos da sociedade civil designados por pró-justiça ${ }^{2}$ de menores, ou seja, organismos da sociedade civil que lutam pela defesa dos direitos dos menores.

Registram-se, com certa frequência no país, casos de menores em conflito com a lei, fenômeno que os dados vão demonstrar, ao longo do trabalho. Sobre esse aspecto, fato preocupante tem a ver com o tratamento que esses menores recebem quando encaminhados para as instituições de Administração da Justiça, particularmente na Polícia. Muitas vezes, esses adolescentes veem os seus direitos sistematicamente violados por parte de alguns membros da Polícia da República de Moçambique (PRM).

Segundo a Fundação para o Desenvolvimento da Comunidade (FDC), esta constitui outra forma de violência exercida pelo Estado ou seus sistemas judiciais, embora seja pouco assumida como tal. É violência porque encoraja, induz e/ ou força a limitação da liberdade, um dos direitos fundamentais da criança (FDC, 2008, p. 26).

Este tipo de violência exercida pelo Estado ou por seus sistemas judiciais contraria um dos dispositivos da Convenção sobre os Direitos da Criança, como abaixo se destaca:

A convenção sobre os Direitos da Criança, no seu artigo 40, frisa que os Estados partes reconhecem o direito à criança suspeita, acusada ou que se reconheceu ter infringido a lei penal, o direito a um tratamento capaz de favorecer o seu sentido de dignidade e valor, reforçar o seu respeito pelos direitos do homem às liberdades fundamentais de terceiro e que tenha em conta a sua idade e a necessidade de facilitar a sua reintegração social e o assumir de um papel construtivo no seio da sociedade (FDC, 2008, p. 26).

Igualmente, esse tipo de violência contraria outras normas internacionais que tratam sobre a justiça de menores, como as que a seguir são mencionadas:

\footnotetext{
2 Como é o caso da "Casa do Gaiato", uma organização privada que se dedica ao atendimento às crianças e aos adolescentes desamparados ou em situação de risco.
}

As normas internacionais incluem ainda três instrumentos especificamente aplicáveis à justiça de menores: as Regras Mínimas das Nações Unidas para a administração de justiça de menores (Regras de Pequim), os princípios orientadores das Nações Unidas para prevenção da delinquência juvenil (princípios orientadores de Riade) e as regras das $\mathrm{Na}$ ções Unidas para a proteção dos menores privados de liberdades (FDC, 2008, p. 26).

Sobre essa questão, constata-se que "em muitos dos países em via de desenvolvimento e/ ou em situações de conflitos, estes dispositivos normativos não são considerados" (FDC, 2008, p. 26). Por isso, revela-se muito importante analisar esse tema, já que Moçambique está no grupo dos países com sérios problemas em lidar com essa problemática de menores em Conflito com a lei.

Igualmente, revela-se de grande importância analisar essa problemática porque, no país, à exceção de Maputo, não existem estabelecimentos estatais educativos para o acolhimento de crianças em situação de conflito com a lei, como afirmam Fumo; José e Samo (2012, p. 34): “(...) À exceção de Maputo (que também está numa situação incipiente), não existem no país estabelecimentos estatais educativos para o acolhimento de menores em conflito com a lei". Mais adiante, os mesmos autores dizem o seguinte:

Quanto aos casos de menores em conflito com a lei, a ausência pode ser explicada, por um lado, pela inexistência de instituições adequadas para lidar com aquele tipo de questões em Moçambique. A precariedade da oferta jurídica e judiciária afasta uma parte considerável da procura potencial. Por outro lado, há muitos casos de menores em conflito com a lei que recebem tratamento inadequado por parte das instituições judiciárias, particularmente a polícia, sendo-lhes aplicadas medidas carcerárias (FUMO; JOSÉ; SAMO, 2012, p. 44).

Apesar de se afirmar que há poucos dados concretos em relação aos números sobre os menores em conflito com a lei no país, devido à falta de banco de dados que forneça com maior exatidão o número real dos menores que se encontram nessa situação, há relatos constantes sobre crianças em situação de conflito com a lei 
que são presas pela polícia ou em algumas unidades prisionais do país; alguns estudos feitos já apresentam dados sobre essa matéria.

Muito recentemente foram detidos nas celas da $1^{\text {a }}$. Esquadra da PRM, da Cidade de Quelimane, na Província moçambicana da Zambézia, um grupo constituído por 20 (vinte) adolescentes designados "meninos da rua" acusados de praticarem assaltos e agressões físicas na via pública (JORNAL "AVERDADE”, 2013).

Um dos estudos do Fundo das Nações Unidas para a Infância (UNICEF), revela que da população prisional em Moçambique com base nos poucos estudos nas províncias de Nampula (localizada no norte do país), Sofala (centro do país) e Maputo (no sul do país), em 2003, pelo menos $25 \%$ dos reclusos entrevistados tinham menos de 18 anos de idade (UNICEF, 2006, p. 185 apud FDC, 2008, p. 27).

Em 2002, um investigador nacional desenvolveu um estudo patrocinado /encomendado pelo Programa das Nações Unidas para o Desenvolvimento (PNUD) que revelou que a população prisional cumprindo pena na Cadeia Central de Maputo, na Cadeia de Máxima Segurança/Unidade Operativa, vulgo "BO" e cadeia Feminina de Ndlavela, localizadas nas cidades de Maputo e na Província de Maputo, respetivamente, havia um número significativo de menores a cumprir penas: dos 685 condenados, 144 eram pessoas de faixa etária dos 16 aos 19 anos, o que corresponde a cerca de $21 \%$ dos condenados (BRITO, 2002).

Os dados estatísticos não espelham de forma clara a magnitude e as características do problema, mas, dentro desse quadro teórico conceitual, os dados recolhidos apontam para a existência de um número expressivo entre $25 \%$ e $30 \%$ e cada vez maior número de crianças em situação de conflito com a lei. (SAVE THE CHILDREN NORWAY MOÇAMBIQUE, 2003).

Os dados acima apresentados espelham claramente a gravidade da situação de menores em conflito com a lei no país, situação esta que requer uma postura mais ousada por parte do Estado e da sociedade moçambicana, no sentido de que casos dessa natureza não continuem a ocorrer no país.

Portanto, baseado num estudo exploratório, recorrendo-se à pesquisa bibliográfica e à análise documental, o presente artigo tem em vista analisar a questão de menores em conflito com a lei em Moçambique, procurando refletir sobre medidas socioeducativas e limites para sua aplicação prática. Sobre pesquisa exploratória, Gil (1999, p. 41) afirma o seguinte:

A pesquisa exploratória é utilizada no momento em que o pesquisador entra em contato com as fontes de coleta de dados, alcançando "maior familiaridade" com o problema, com vistas a torná-lo mais explícito ou a construir hipóteses (...) que facilitam o seu encadeamento e realização.

\section{Considerações acerca do histórico da legislação sobre criança, adolescentes ou menores no país}

Antes de falarmos das considerações acerca do histórico da legislação sobre crianças, adolescentes ou menores no país, é importante clarificar dois pontos. Um deles tem a ver com a designação dos conceitos de criança, adolescente e menor. Sobre esse ponto, a legislação nacional não distingue diferença entre esses conceitos. Ela só define a faixa etária sobre quem deve ser considerado criança ou menor e, o termo menor, como dissemos anteriormente, não tem um teor pejorativo ou ofensivo no país. $\mathrm{E}$ o termo adolescente não é muito usual nesse contexto da legislação nacional. O outro ponto tem a ver sobre o indivíduo que deve ser considerado criança ou menor no país.

Segundo o $n^{\circ} 1$ do artigo 3 da Lei $7 / 2008$, "considera-se criança toda a pessoa menor de dezoito anos de idade". Entretanto, segundo o $n^{\circ} 2$ do artigo 3 da Lei 7/2008, "nos casos expressamente previstos, a presente Lei aplica-se também aos menores com mais de dezoito e menos de vinte e um anos de idade".

Em relação à definição dessa baliza de idade, afirma-se o seguinte:

No que se refere ao conceito de criança, depois de considerados vários fatores atinentes ao desenvolvimento da criança e ao estabelecido na Convenção sobre os Direitos da Criança, decidiu-se acolher a regra estabelecida no Direito Internacional, que considera criança, todo o menor de 18 anos. Entendeu-se, entretanto, que deveria estender a aplicação da Lei aos maiores de 18 e menores de 21 , sempre que tal se justifique (ISSÁ, 2008, p. 18). 
Tal como no mundo, a " legislação relativa a menores em Moçambique não evolui de forma linear, tendo refletido as dinâmicas políticas, econômicas, sociais e institucionais do país" (FUMO; JOSÉ; SAMO, 2012, p. 20).

Como corolário do reconhecimento dos problemas que afetam a criança, Moçambique fez, em 1979, pela resolução $n^{\circ} 23 / 79$ de 28 de dezembro, a "Declaração dos Direitos da Criança Moçambicana", uma resposta do governo e da Assembleia Legislativa ao fato de o ano de 1979 ter sido declarado pelas Nações Unidas o ano internacional da criança (FDC, 2008, p. 13).

A Constituição de 1990 representa uma viragem no tratamento das questões relativas aos menores em Moçambique por via da lei, ao preconizar que a maternidade é dignificada e protegida; a família, a sociedade e o Estado são responsáveis pela educação, pelo desenvolvimento harmonioso e pela proteção da criança: e que a criança não pode ser discriminada, designadamente, em razão do seu nascimento, nem sujeita a maus tratos (FUMO; JOSÉ; SAMO, 2012).

Vale notar que na Constituição de 1975, designada Constituição da República Popular de Moçambique (CRPM), nenhum artigo desta fazia referência a criança ou menor de idade.

Com a Constituição da República de Moçambique (CRM) de 2004, consolida-se aspectos atinentes à proteção dos direitos das crianças e dos adolescentes. Como na Constituição de 1990, a Constituição de 2004 dedica igualmente alguns artigos sobre os direitos da criança. Essa constatação confirma-se logo no artigo 40 da mesma, no qual se define o seguinte:

1. as crianças têm direito à proteção e aos cuidados necessários ao seu bem-estar;

2. as crianças podem exprimir livremente a sua opinião, nos assuntos que lhes dizem respeito, em função da sua idade e maturidade;

3. todos os atos relativos às crianças, quer praticados pelas entidades públicas, quer por instituições privadas, têm principalmente em conta o interesse superior da criança.

Posteriormente, no artigo 120, afirma-se que "a família é responsável pelo crescimento harmonioso da criança, educa as novas gerações nos valores morais, ético e socais" ( $\mathrm{n}^{\circ} 2$ do artigo 120 da CRM, 2004); sobre o papel da Família e do Estado, diz-se que "a família e o Estado asseguram a educação da criança, formando-a nos valores da unidade nacional, no amor à pátria, igualdade entre homens e mulher, respeito e solidariedade social" ( $\mathrm{n}^{\circ} 3$ do artigo 120 da CRM, 2004).

Seguidamente, fala-se da infância nos seguintes termos:

1. todas as crianças têm o direito à proteção da família, da sociedade e do Estado, tendo em vista o seu desenvolvimento integral;

2. as crianças, particularmente as órfãs, as portadoras de deficiências e as abandonadas, têm proteção da família, da sociedade e do Estado, contra qualquer forma de discriminação, de maus tratos e contra o exercício abusivo da autoridade na família e nas demais instituições.

3. a criança não pode ser discriminada, designadamente, em razão do seu nascimento, nem sujeita a maus tratos;

4. é proibido o trabalho da criança quer em idade de escolaridade obrigatória quer em qualquer outra (Artigo 121 da CRM, 2004).

É importante notar que o país alcança a independência do jugo colonial português em 1975. No entanto, só no ano de 2008 que foi aprovada uma série de leis de promoção e proteção dos direitos da criança com conteúdos mais abrangentes e completos no que tange aos direitos da criança ou do menor. Essa demora na criação de uma legislação que proteja integralmente os direitos da criança no país contribui significativamente para que até agora alguns aspectos sobre os direitos da criança não sejam devidamente salvaguardados.

Destaca-se, nessas leis aprovadas em 2008, a lei $n^{\circ} 7 / 2008$, de 09 de julho ${ }^{3}$, que pode ser considerada como o estatuto de criança ou de menores de Moçambique, dada a significativa abrangência e da forma como articula todos os aspectos de direitos que são relevantes na pro-

\footnotetext{
${ }^{3} \mathrm{~A}$ definição do conceito de criança consta nesta lei.
} 
moção e na proteção dos direitos da criança e do menor de idade no país. Essa lei é designada, às vezes, como a lei de Bases de Proteção de Criança, e outras vezes, como lei de Promoção e Proteção do Direito da Criança.

De acordo com artigo $1^{\circ}$ desa lei ${ }^{4}$, a mesma tem por objeto a proteção da criança e visa reformar, estender, promover e proteger os direitos da criança, tal como se encontram definidos na Constituição da República, na Convenção sobre os Direitos da Criança, na Carta Africana sobre os Direitos e o Bem-estar da Criança e demais legislação de proteção à criança.

No artigo 4 dessa mesma lei, sobre os direitos fundamentais, afirma-se o seguinte:

1. a criança goza de todos direitos fundamentais inerentes à pessoa humana, sem prejuízo da proteção integral de que trata a presente lei, assegurando-lhe, através do adequado quadro jurídico e outros meios, todas as oportunidades e facilidades, a fim de lhe facultar o desenvolvimento físico, mental, moral, espiritual e social, em condições de liberdade e de dignidade;

a criança não pode ser discriminada, nomeadamente em razão da cor, raça, sexo, religião, etnia, origem de nascimento, condição socioeconômica, estado de saúde e deficiência.

No artigo 6, aparece estatuída uma questão muito importante a ser levada em conta, ao se dizer que nenhuma criança pode ser sujeita a tratamento negligente, discriminatório, violento e cruel, nem ser objeto de qualquer forma de exploração ou opressão, sendo punidos por lei todos os atos que se traduzam em violação dos princípios ora estabelecidos.

Igualmente, outro aspecto importante vem estabelecido no artigo 9, referente a interpretação e aplicação, ao se prever o seguinte:

1. na interpretação da presente lei deve terse em conta os superiores interesses da criança, os fins sociais a que ela se dirige, as exigências do bem comum, os direitos e deveres individuais e coletivos e a condição especial da criança como pessoa em desenvolvimento;

${ }^{4}$ Lei $\mathrm{n}^{\circ} .7 / 2008$ de 09 de Julho.
2. em caso de existir norma legal menos protetora ou menos promotora dos direitos da criança, sobrelevam sempre os princípios e as disposições da presente Lei;

3. para efeitos da presente Lei, entende-se por superior interesse da criança tudo o que tem a ver com a defesa e salvaguarda da sua integridade, identidade, manutenção e desenvolvimento são e harmonioso.

Nessa mesma lei define-se os direitos e deveres da criança. Igualmente, tratam-se as medidas de proteção, incluindo situações de criança ou menores em conflito com a lei e medidas socioeducativas. Esses assuntos que têm a ver com situações de criança ou menores em conflito com a lei serão objeto de tratamento específico quando chegar a vez de falarmos sobre medidas socioeducativas e limites para a sua aplicação prática.

Como havia dito anteriormente, em 2008 foi aprovada uma série de leis sobre a proteção e promoção dos direitos da criança. Aprovou-se igualmente neste ano, a Lei $n^{\circ} 08 / 2008$, designada Lei da Organização Jurisdicional de Menores, de 15 de julho.

Segundo informações disponíveis, "Até o presente momento, o direito processual referente à jurisdição de menores achava-se contido, essencialmente, no Estatuto de Assistência Jurisdicional de Menores, aprovado pelo Decreto $n^{\circ}$ 484/71, de 08 de novembro" (ISSÁ, 2008, p. 69).

Fazendo referências a esses dois instrumentos legais, por ele mencionados, o autor afirma o seguinte:

Os dois instrumentos legais acima mencionados encontravam-se, em muito dos seus aspectos ultrapassados e desajustados à realidade. Por outro lado, em muitas vertentes, o Estatuto e seu Regulamento não chegaram a ter qualquer aplicação prática, designadamente, no que dissesse respeito aos serviços de assistência social, de observação e aos estabelecimentos de prevenção criminal previstos no Estatuto e Regulamento. Na verdade, aqueles serviços e instituições nunca chegaram a funcionar tal como foram concedidos (ISSÁ, 2008, p. 69).

A recente entrada em vigor da Constituição da República de Moçambique, da Lei n 10/2004, de 25 de agosto, da lei da Família, aprovada pela 
Lei $n^{\circ}$ 10/2004, de 25 de agosto, do Código de Registo Civil, aprovado pela Lei $n^{\circ} 12 / 2004$, de 08 de dezembro, tornaram também imperiosa e inadiável a revisão do Estatuto de Assistência Jurisdicional de Menores (ISSÁ, 2008, p. 69).

Mais adiante, sobre essa reforma da jurisdição de menores, afirma-se o seguinte:

Com esta reforma cremos que se eliminarão ou se reduzirão, de forma substancial, não só vazios de lei, como também as dúvidas que se suscitavam na interpretação e aplicação das normas processuais respeitantes a menores, quer na vertente de sua recuperação (menores em conflito com a lei), quer na vertente de proteção. E, com a introdução de novas formas de proteção, ficam melhor salvaguardados os superiores interesses da criança moçambicana (ISSÁ, 2008, p. 72).

Sobre objeto e fins da jurisdição de menores, preceitua-se que a jurisdição de menores tem por objeto e finalidade garantir a assistência aos menores no domínio da prevenção criminal, mediante aplicação de medidas de proteção, assistência ou educação e no domínio da defesa dos seus direitos ou interesses, mediante a adoção de providências cíveis adequadas (Artigo 1 da lei $\left.n^{\circ} 8 / 2008\right)$.

Ainda em 2008, aprovou-se a Lei $n^{\circ}$ 6/2008, de 09 de julho, lei sobre o Tráfico de Pessoas. Essa lei tem por objeto estabelecer o regime jurídico aplicável à prevenção e ao combate ao tráfico de pessoas, em particular mulheres e crianças, nomeadamente a criminalização do tráfico de pessoas e atividades conexas e a proteção das vítimas, denunciantes e testemunhas.

Igualmente, existe no país a lei da família, que prevê também a proteção dos direitos das crianças, como podemos constatar na alínea c), artigo $4^{\circ}$, sobre um dos deveres da família: "garantir o crescimento e desenvolvimento integral da criança, do adolescente e do jovem".

Em Moçambique encontramos ainda outras leis que tratam acerca dos direitos das crianças, destacando-se a nova lei do trabalho, a Lei $n^{\circ}$ 23/2007, de 01 de agosto que traz consigo alguns preceitos legais sobre as medidas que os empregadores devem adotar, no sentido de proporcionar ao menor condições de trabaIho adequadas a sua idade, saúde, segurança, educação e formação profissional, prevenindo quaisquer danos ao seu desenvolvimento físico, psíquico e moral e além de aspectos inerentes ao menor no âmbito da legislação laboral; da Lei de Interdição ao acesso de Menores a Clubes Noturnos e do Código Penal. Sobre o Código Penal importa ressaltar que em um dos seus dispositivos estatui-se que os menores de 16 anos são inimputáveis em razão da idade.

Podemos destacar igualmente alguns documentos que foram criados com o fim de assegurar a proteção dos direitos da criança e do adolescente, como o Plano Nacional de Ação para a Criança, a Estratégia da Ação Social para a Criança e o Plano de Ação para as Crianças Órfãs e Vulneráveis, aprovados em 2006.

Vale notar igualmente o Decreto 08/2008, de 31 de março, que cria o Conselho Nacional dos Direitos da Criança, resultante da exigência imposta pela Lei $n^{\circ} 7 / 2008$ de 09 de julho, Lei de Promoção e Proteção do Direito da Criança que, no seu artigo 71, remetia ao Governo a competência de regulamentar a composição, o funcionamento e a competência do Conselho Nacional dos Direitos da Criança, fato concretizado com a criação e a aprovação desse decreto. Esse conselho tem como objetivos supervisionar, impulsionar e acompanhar a implementação de políticas e programas aprovados pelo governo na área da criança.

No plano dos instrumentos internacionais que asseguram a proteção dos direitos da criança, importa referir que Moçambique ratificou uma boa parte desses instrumentos internacionais, destacando-se a Convenção das Nações Unidas Sobre os Direitos da Criança, ratificada pela Resolução n 19/90, de 23 de outubro; a Carta Africana dos Direitos e Bem-estar da Criança adotada pelos Estados africanos, membros da OUA (Organização da Unidade Africana), agora UA (União Africana), ratificada através da Resolução n 43/2002 de 28 de maio; a Convenção $\mathrm{n}^{\circ} 138$, sobre a idade mínima de admissão no emprego, de 1973, no contexto da prossecução dos objetivos da Organização Internacional de Trabalho (OIT), ratificada através da Resolução $n^{\circ}$ 5/2003 de 23 de abril e a Convenção $n^{\circ} 138$, relativa à interdição das Piores Formas de Trabalho das Crianças e à ação imediata com vista a sua eliminação, ratificada pela Resolução $n^{\circ}$ 6/2003, de 23 de abril. 


\section{Reflexões sobre medidas socioeducativas e limites para sua aplicação prática}

O país enfrenta hoje um grande desafio na implementação prática de instrumentos legais aprovados na área da criança ou de menores. Em muitos dos instrumentos legais aprovados, a maior parte dos seus preceitos legais ainda carece de materialização, principalmente aquelas disposições legais que têm a ver com as medidas socioeducativas nos casos de menores que cometem algum ato infracional.

Moçambique tem cerca de 20,5 milhões de habitantes, dos quais cerca de $50 \%$ são menores de 18 anos. Estes dados sugerem que uma parte significativa dos esforços de desenvolvimento de Moçambique deverá estar direcionada para as crianças (FUMO; JOSÉ; SAMO, 2012, p. 16).

Na nossa opinião, consideramos que na área da criança, alguma parte desses esforços deve ser direcionada nos casos de menores em conflito com a lei, na adoção e na implementação prática de medidas socioeducativas claras e também direcionando recursos para se ultrapassar os obstáculos que impedem a concretização dessas medidas.

Os problemas que afetam as vidas e o desenvolvimento das crianças são de várias ordens atravessando a esfera da família, da comunidade e do Estado, e registrando-se nas mais diversas áreas, nomeadamente educação, cultura, saúde, justiça, trabalho, etc. (FUMO; JOSÉ; SAMO, 2012, p.17). Na área da justiça, como temos dito, o maior desafio tem a ver com a implementação prática das medidas socioeducativas.

Antes de entrarmos em detalhes acerca das medidas a serem consideradas em situações de menores em conflito com a lei no país, importa primeiro, situar o conceito do ato delitivo segundo a legislação de menores em Moçambique.

Para legislação de menores, "considera-se ato delitivo a conduta da criança descrita como infração criminal ou contravencional pela legislação penal" (artigo 81 da Lei 07/2008).

Portanto, segundo essa lei, para que a conduta da criança seja considerada infração criminal ou contravencional, tem que estar descrita na lei. Esse pormenor é muito importante, porque evita que qualquer conduta de uma criança seja considerada uma infração criminal ou contravencional.
Para os casos de crianças ou menores com idade maior de 16 anos e menor de 18 anos, a lei prevê que, se o crime for de pequena gravidade, seja aplicada medida alternativa como se constata a seguir: "À criança maior de 16 anos e menor de 18 anos que comete crime de pequena gravidade deve aplicar-se, sempre que possível, medida alternativa à prisão" (artigo 84 da Lei 07/2008). A definição dessa faixa etária também vem refletida no Código Penal moçambicano, anteriormente referida, como um dos instrumentos legais que tratam sobre os direitos da criança ou do menor no país.

Já para casos de menores de 16 anos, o entendimento legal sobre essa matéria é diferente, pois a lei impede em absoluto a aplicação de medidas privativas da liberdade: "a criança com menos de 16 anos não pode ser sujeita a medidas de privação de liberdade, apenas se lhe podendo aplicar as medidas tutelares previstas por lei" (artigo 83 da Lei 07/2008).

Posto isso, importa agora abordar sobre as medidas que podem ser aplicadas quando um menor comete uma infração criminal ou contravencional. Para se fazer face a essa questão de menores em conflito com a lei, essa define várias medidas de prevenção criminal. Segundo o artigo 92 da Lei 07/ 2007, as medidas socioeducativas e as respectivas regras estão definidas na legislação de menores e na legislação prisional.

No que se refere a aplicação dessas medidas,

O tribunal é livre de escolher, entre as medidas aplicáveis, a que se mostrar mais adequada a cada caso, tendo sempre em conta o grau de censura social atribuído à conduta do menor, da sua ressocialização social, a exequibilidade prática daquelas, as possibilidades reais das instituições e as demais circunstâncias concretas que interessam à eficácia da medida decretada ( $n^{\circ} 1$ do artigo 28 , da Lei $n^{\circ}$ 7/2008).

Neste sentido, a lei define que, aos menores que se encontrem sujeitos à jurisdição dos tribunais de menores são aplicáveis, isolada ou cumulativamente, as seguinte medidas:

a) repreensão registrada;

b) entrega à responsabilidade dos pais, tutor, família de acolhimento ou pessoa encarregada pela sua guarda; 
c) Caução de boa conduta;

d) liberdade assistida;

d) proibição de frequentar determinados recintos ou locais por período certo de tempo ou de acompanhar com certo tipo de pessoas;

e) assistência médico-psicológica;

f) colocação em família idônea ou em estabelecimento oficial de educação, em regime de semiaberto;

g) colocação, em regime de internato, em escola de formação vocacional;

h) Internamento em estabelecimento de recuperação juvenil;

i) obrigação de reparar o dano (artigo 27 da Lei 08/2008).

Recorrendo à lei acima mencionada, passamos a seguir, ao detalhamento das regras ou circunstâncias em que cada medida deve ser aplicada pelo tribunal de menores. Entretanto, não fazemos menção desses detalhes sobre as medidas referentes as alíneas a) e b) do artigo 27 da Lei 08/2008 porque o legislador não faz referência sobre essas duas medidas, no que tange às circunstâncias em que devem ser aplicadas.

Desse modo, a caução de boa conduta é aplicada e exigida quando o menor exercer qualquer atividade remunerada e prestada por depósito, em valor a fixar pelo juiz, que não pode exceder o correspondente a três salários mínimos nacionais. Importa referir que essa caução é prestada por período de tempo até dois anos, podendo ser prorrogado por período anuais, e pode ser declarada perdida nos termos do $\mathrm{n}^{\circ} 2$ do artigo 30 da presente lei.

Acerca da liberdade assistida, legalmente recomenda-se que o menor a quem tiver sido aplicada essa medida esteja sujeito a observação e acompanhamento periódico por parte dos serviços da ação social em coordenação com as autoridades do seu local de residência; quando adotar a medida de liberdade assistida, o tribunal fixa os deveres a que o menor fica especialmente sujeito em matéria de conduta social, instrução, preparação profissional e utilização de tempo livre, bem como definir as obrigações das pessoas a quem esteja confiado.

No caso de proibição de frequentar certo tipo de recinto ou locas, vale realçar que, nesse caso, o tribunal fixa, com precisão, os recintos e locais interditos ao menor, assim como as pes- soas com quem não pode ser acompanhado, e determina o período de tempo da vigência da medida. Aqui também se dá a conhecer às autoridades do local de residência do menor, a fim de exercerem a devida vigilância e informarem ao tribunal da evolução do seu comportamento.

Aassistência médico-psicológica é aplicada ao menor, sempre que a sua conduta antissocial evidencie ter sido condicionada por desvio forte da sua personalidade e exija a intervenção de especialista para sua recuperação, pode ser aplicada em regime de internamento ou semiinternamento em estabelecimento apropriado.

A colocação em família idônea ou em estabelecimento oficial de educação acontece quando a conduta do menor se revele pouco grave e houver família disposta a acompanhálo ou estabelecimento educacional que possa frequentar, inclusive em regime de internato.

A medida de internamento em escola de artes e ofícios é aplicável ao menor que não revele tendência criminosa, mas evidencie conduta motivada por instabilidade sóciofamiliar.

A medida de internamento em estabelecimento de recuperação juvenil é aplicável ao menor que revele grave desvio sóciofamiliar com comportamento violento, que evidencie conduta antissocial com tendência criminosa, ou que pratique fatos delitivos que constituam infração criminal de relativa gravidade.

A obrigação de reparar o dano é aplicável ao menor, isolada ou cumulativamente, sempre que a sua conduta tenha provocado danos a terceiros que importe repor, independentemente do nível de gravidade da sua conduta.

Os estabelecimentos de prevenção criminal, acima descritos, têm como fins, segundo o artigo 157 da Lei 08/2008:

1. garantir a recuperação social dos menores e destinar-se à observação, assistência e execução de medidas de prevenção criminal;

2. no âmbito geral de estabelecimento de prevenção criminal incluem-se as unidades de observação e de assistência medico-psicologica, bem como os estabelecimentos de recuperação juvenil;

3. cabe ao Governo providenciar pela criação dos estabelecimentos indicados neste artigo. 
Entretanto, os tais estabelecimentos de prevenção criminal praticamente não existem no país. O governo que tem a responsabilidade de velar pela criação dos aludidos estabelecimentos de prevenção ainda não os criou, dificultando a aplicação prática das medidas de prevenção criminal. Por isso, "Relativamente às medidas tutelares acima indicadas, cabe dizer que, de uma forma geral, elas se encontram completamente desajustadas da realidade moçambicana, sendo, por isso, de concretização praticamente impossível" (SAVE THE CHILDREN NORWAY MOÇAMBIQUE, 2003).

Por sua vez, sobre esse mesmo aspecto, Fumo; José e Samo (2012, p. 81-82), afirmam o seguinte:

Porém, a informação dos magistrados entrevistados revela-nos que, dentre todas as medidas decretáveis, apenas as primeiras três são efetivamente aplicadas, designadamente a repreensão registada; a entrega à responsabilidade dos pais, tutor, família de acolhimento ou pessoa encarregada pela sua guarda; e a caução de boa conduta. As restantes 8 não são aplicáveis em virtude de se revelarem manifestamente ineficazes face à ausência quase total de mecanismos de controlo e de recursos materiais (como casas de internamento) e de pessoas especializadas para prestar assistência ao menor. Outro ponto fraco do sistema nacional de justiça de menores prende-se com a inexistência quase total de estabelecimentos de prevenção criminal.

Refira-se, entretanto, que entre 1978 e 1984, o Governo moçambicano procurou instalar em cada uma das províncias do país centros de recuperação de menores, com algumas características de institutos educacionais. Centros estes que acabaram por desaparecer com o alastramento da guerra ${ }^{5}$ (SAVE THE CHILDREN NORMAY MOÇAMBIQUE, 2003).

A mesma organização registra o seguinte:

Contudo, nos últimos 20 anos tem-se vindo a assistir a uma completa apatia por parte do Estado em relação à adoção de medidas apropriadas quanto à prevenção e tratamento da delinquência juvenil, razão pela qual a

\footnotetext{
${ }^{5}$ Guerra civil terminada em 1992, que opunha o exercito governamental e a RENAMO (Resistência Nacional de Moçambique).
}

jurisdição de menores se tem demonstrado inoperante nesse domínio, ao mesmo tempo que se verifica, por outro lado, uma atuação da polícia, contrária aos princípios constitucionais e à lei ordinária (SAVE THE CHILDREN NORMAY MOÇAMBIQUE, 2003).

Entretanto, vale dizer que o governo nos últimos tempos, adotou algumas medidas para enfrentar essa problemática, no quadro da legislação de menores. O calcanhar de Aquiles continua sendo a criação de estabelecimentos adequados para o internamento dos menores em conflito com a lei. A falta de estabelecimentos para o internamento de menores infratores constitui um fator determinante que limita profundamente a implementação prática das medidas socioeducativas.

O governo aprovou, no ano de 2002, a resolução $n^{\circ}$ 65/2002 de 27 de agosto, que dispõe sobre política prisional em Moçambique e a estratégia da sua implementação. Com a aprovação dessa resolução, parecia que o estágio das coisas sobre essa questão poderia melhorar num horizonte não muito longo, mas a realidade demonstra que a efetivação das propostas presentes nessa resolução levará ainda muito tempo.

Essa resolução tem o objetivo de introduzir uma reforma perante a situação crítica em que se encontra o sistema prisional nacional, criando condições para tornar realidade, no funcionamento dos estabelecimentos prisionais, o respeito das Regras Mínimas das Nações Unidas Sobre o Tratamento dos Reclusos e a concretização das recomendações expressas na Declaração de Kampala, nomeadamente no que respeita à promoção de mecanismos de tratamento de reclusos e dos meios alternativos à privação de liberdade.

Essa resolução sobre política prisional e estratégia de implementação define várias medidas que podem alterar profundamente a situação prevalecente no sistema prisional moçambicano. Ela remete a uma legislação específica para a classificação dos estabelecimentos, como podemos constatar a seguir:

Nesse sentido, a legislação pertinente estabelecerá a classificação dos estabelecimentos de acordo com o regime de cumprimento de penas, destacando-se: a) estabelecimentos 
da prisão preventiva; b) estabelecimentos de cumprimento de pena, classificados de acordo com o regime de progressividade da pena e de sua dimensão, incluindo centros prisionais abertos; c) estabelecimentos especiais, incluindo os destinados aos menores inimputáveis (RESOLUÇÃO N 65/2002).

Como podemos notar, na última classificação dos estabelecimentos prisionais de acordo com o regime de cumprimento de penas, inclui-se os destinados aos menores inimputáveis. Esse fato gerou muita expectativa no seio da sociedade no geral e dos organismos da sociedade civil que lidam com a matéria dos direitos da criança, em particular, porque pensava-se que finalmente o problema de quase ausência de estabelecimentos destinados aos menores em conflito com a lei no país chegaria ao fim num curto espaço de tempo. Mas não foi isso que aconteceu e o projeto dessa classificação dos estabelecimentos prisionais ainda não foi materializado.

Continuando sobre as medidas de prevenção criminal, a coordenação para aplicação das medidas de prevenção criminal é feita da seguinte maneira:

1. o Ministério de Justiça, em coordenação com os Serviços da Ação Social e outras entidades e serviços do Estado ligados à área de atendimento de menores, criam condições para que possam ser postos em prática mecanismos de coordenação permanente com instituições públicas e privadas, que se dediquem à assistência, proteção e educação da criança, de modo a poder concretizar-se a aplicação das medidas de prevenção criminal, tendentes a garantir a recuperação e readaptação do menor;

2. enquanto não forem criadas as instituições previstas no presente diploma legal e não tendo sido estabelecidos mecanismos nos termos do número anterior, o tribunal de menores pode tomar as medidas que considerar convenientes, recorrendo para o efeito a instituições públicas e privadas vocacionadas ao atendimento, assistência, proteção e educação de menores, para fins previstos no número anterior;

3. é dever das instituições públicas e privadas colaborarem, de forma planificada, com os tribunais de menores para permitir a exequibilidade das medidas de prevenção (artigo 159 da Lei 08/2008).
O legislador, prevendo dificuldades na implementação prática das medidas de prevenção criminal, abriu espaço para a delegação de competência de assistência, proteção e educação de menores às outras instituições públicas e ao setor privado. A experiência demonstra que praticamente é o setor privado que toma conta dessa missão de assistência e proteção de menores. Nesse sentido, "não tendo o Estado instituições adequadas para acolher crianças em conflito com a lei, quem assume esse papel é a sociedade civil"6

Por sua vez, a recuperação social de menores, é feita nos seguintes termos:

1. a recuperação e readaptação social dos menores, através de educação adequada e instrução escolar e aprendizagem de uma profissão, é feita nas instituições de educação e formação profissional do Estado;

2. em função das dificuldades educativas e disciplinares que os menores ofereçam, é selecionado o estabelecimento apropriado (artigo 162, Lei 08/2008).

$\mathrm{Na}$ prossecussão das suas atividades, esses estabelecimentos de recuperação juvenil têm por missão "proceder à recuperação e readaptação social dos menores, através de ações educativas, formativas e de preparação profissional, tendentes a garantir a sua autossustentabilidade e uma correta reinserção na sociedade" ( $n^{\circ} 1$, artigo 163 da Lei 08/2008).

Sobre entidades a que forem confiadas a administração de estabelecimento de prevenção criminal, acautela-se que a sua atuação seja como a lei impõe:

As entidades a quem for confiada a administração de estabelecimento de prevenção criminal tomam a seu cargo a educação, a instrução escolar e a preparação profissional dos menores segundo os seus próprios métodos, salvaguardando a observância das disposições gerais da presente Lei que não forem expressamente excluídas por acordo entre a entendida responsável pela administração do estabelecimento e o Ministério da Justiça ( $\mathrm{n} 1$, do artigo 165 da Lei 08/2008).

\footnotetext{
${ }^{6}$ Resposta de uma magistrada, numa entrevista feita por Fumo; José e Samo (2012, p. 56)
} 
Portanto, legalmente estão previstas várias ações que têm a ver com a aplicação de medidas de prevenção criminal, ou seja medidas socioeducativas, mas quase todas as medidas previstas não são aplicadas por falta de estabelecimentos apropriados para o efeito.

Outro aspecto que limita a aplicação prática das medidas socioeducativas tem a ver com a falta de pessoal especializado e qualificado suficientemente no país em matéria de aplicação dessas medidas, em todos setores do Estado que de alguma forma ou de outra intervêm nesse processo. Destes, podemos destacar o pessoal da ação social, justiça/prisional, da polícia etc.

Os autores Fumo; José e Samo (2012, p.

34) notam o seguinte:

[...] O funcionamento em rede das instituições pode favorecer o acesso à justiça. Como se sabe, Moçambique está longe de assegurar o desenvolvimento paritário das diversas instituições, o que tem resultado numa administração de justiça bastante problemática. A título de exemplo, na cidade de Pemba existem apenas três técnicos da ação social que procuram, da melhor forma, responder às solicitações, devendo inclusivamente deslocar-se aos distritos que não dispõem de técnicos. Ainda assim, dadas as carências de meios, as deslocações aos distritos sucedem sobretudo quando há outras atividades da Direção Provincial para cumprir.

O caso da cidade de $\mathrm{Pemba}^{7}$ demonstra claramente como a falta de pessoal especializado e qualificado em número suficiente limita a implementação das medidas socioeducativas. Faz-se referência, neste caso, o número dos assistentes sociais disponíveis que devem cobrir outros distritos da província que não tenham tais assistentes. Aliás, importa dizer que mesmo os distritos que têm esses profissionais não devem possuir de mais de um assistente social por cada distrito.

Na cidade de Maputo, onde temos o único Tribunal de Menores do país, verifica-se igualmente a carência desses profissionais. O número de assistentes sociais disponíveis no Tribunal de Menores não é suficiente para responder

${ }^{7}$ Cidade moçambicana localizada na Província de Cabo Delegado, na região norte do país. satisfatoriamente à demanda processual. Essas limitações fazem com que os assistentes sociais nem sempre se possam deslocar ao terreno para colherem elementos seguros para os inquéritos (FUMO; JOSÉ; SAMO, 2012, p. 56).

\section{Considerações finais}

A criação e a consequente aprovação da Lei de Promoção e Proteção de Direito da Criança, da Lei da Organização Jurisdicional de Menores e da Lei sobre o Tráfico de Pessoas, em 2008, constituiu um marco importante na área de proteção dos direitos da criança no país. Não é por acaso que um estudo recente, desenvolvido e publicado em Londres pelo Centro da Análise de Política Mundial da Universidade da Califórnia Los Angeles (UCLS), coloca Moçambique como um dos países que lideram uma lista mundial em algumas políticas de proteção de crianças.

Importa dizer ainda que várias ações que visam a salvaguarda e proteção plena dos direitos da criança no país estão sendo desenvolvidos ao nível governamental. No entanto, alguns aspectos, como os casos de aplicação prática de medidas socioeducativas, designadas de medidas de prevenção criminal, aos menores em conflito com a lei, continuam preocupantes.

Sobre essa questão, Fumo; José e Samo (2012, p. 19), reforçam nosso posicionamento ao afirmar:

Todavia, apesar dos esforços assinaláveis no campo jurídico e administrativo por parte do poder público moçambicano, a verdade é que Moçambique ainda enfrenta grandes desafios no sentido de assegurar o exercício efetivo dos direitos das crianças. No que diz respeito ao acesso à justiça de menores apesar de se encontrar salvaguardado constitucionalmente, apenas uma ínfima parte dos menores tem os seus direitos garantidos.

Apesar de o quadro legal ser consideravelmente favorável, no país continuamos com quase todos os velhos problemas que limitam a aplicação prática das medidas socioeducativas, aos menores em situação de conflito com a lei. O problema de falta quase total de estabelecimentos estatais apropriados de prevenção criminal ou de aplicação de medidas socioeducativas ainda prevalece. 
Ao longo da história de Moçambique, fala-se da existência de um centro, denominado "Centro de Chiango", criado logo após a independência nacional que tinha alguma natureza de centro de recuperação de menores infratores. Todavia, desconhecem-se as causas que levaram ao seu encerramento.

Entre 1978 e 1984, tentou-se instalar em cada uma das províncias do país centros de recuperação de menores, porém, importa referenciar que o modelo adotado naquela altura não poderia contribuir devidamente para a recuperação de menores delinquentes, por sua estrutura organizativa e de direção ser demasiado política e militar, hostilizando as crianças que neles eram internadas (SACRAMENTO, 1986).

Atualmente, contamos no país com um Centro de Reabilitação Juvenil de Menores de Boane, localizado na Província de Maputo (na zona sul de Moçambique), que pode ser considerado o único centro do gênero no país que atende especificamente os casos de internamento de menores infratores.

Outra questão que limita a aplicação prática das medidas socioeducativas no país, e que ainda prevalece sem solução, tem a ver com a falta de pessoal especializado e qualificado suficientemente para lidar com essa problemática de menores em conflito com a lei, ao nível dos setores da Ação Social, da Justiça Prisional e mesmo na Polícia, como no item anterior tentamos demonstrar.

Para finalizar, entendemos que medidas urgentes são necessárias para que se resolvam os aspectos relacionados com a falta de estabelecimentos para menores em conflito com a lei e a falta de pessoal qualificado e especializado no país. A realidade nos demonstra que os maiores desafios na implementação prática das medidas socioeducativas no país circunscrevem-se na busca de solução para que se ultrapasse esses dois aspectos que limitam profundamente a implementação prática dessas medidas.

Portanto, voltamos a sublinhar que o quadro legal sobre a definição das medidas socioeducativas no país é favorável. Mas esse fato apenas não basta. É necessário que sejam criadas condições para a sua implementação prática, desde as condições de infraestrutura ao pessoal qualificado e especializado em número suficiente. Dessa forma, o Estado estaria a cum- prir com os propósitos que levaram a adoção de medidas socioeducativas, designadas de medidas de prevenção criminal nos casos de menores em conflito com a lei. E, "(...) deste modo, protege-se o direito da criança ao crescimento num ambiente são, o direito à educação no seio da própria sociedade, família e o direito a um tratamento diferenciado pelas instituições penais, em resultado do princípio da inimputabilidade dos menores de 16 anos" (ISSÁ, 2008, p. 26-27).

\section{Referências}

BRITO, L. Os Condenados de Maputo. Programa PNUD de Apoio ao Setor da Justiça. Maputo: CEIDIMA, 2002.

FUMO, J; JOSÉ, A.C; SAMO, A. S. Estudo Diagnóstico da Justiça de Menores. Maputo: CEIDIMA, 2012.

GIL, A. Métodos e Técnicas de Pesquisa Social. $5^{a}$ Ed., São Paulo: Editoras Atlas, 1999.

JORNAL AVERDADE, Maputo. 04 de Abril de 2013.

ISSÁ, A.C.M. Lei de Base de Proteção da Criança, Lei da Organização Jurisdicional de Menores e Lei Sobre o Tráfico de Pessoas. Maputo: Central Impressora e Editora de Maputo, 2008.

MOÇAMBIQUE. Constituição (1990). Constituição da República de Moçambique, de 02 de novembro de 1990. Boletim da República, Maputo, 02 de novembro de 1990, I Série-Número 44.

MOÇAMBIQUE. Constituição (2004). Constituição da República de Moçambique, de 16 de novembro de 2004. Boletim da República, Maputo, 22 de dezembro de 2004, I Série-Número 51.

MOÇAMBIQUE. Lei $n^{\circ}$ 10/2004 de 25 de agosto, que prova a Lei da Família e revoga o Livro IV do Código Civil. Maputo: Imprensa Nacional de Moçambique, 2004.

MOÇAMBIQUE. Resolução n 65/2002, que dispõe sobre Política Prisional e Estratégia da sua Implementação. Boletim da República, Maputo, 27 de agosto de 2002.

MOÇAMBIQUE-INE. III Recenseamento Geral da População e Habitação 2007. Resultados Definitivos. Maputo, 2010.

SACRAMENTO, L. F. "Delinquência Juvenil Prevenção e Tratamento”. In Revista Popular, 1986. 
SAVE THE CHILDREN NORWAY MOÇAMBIQUE.

Relatório Preliminar da Pesquisa Sobre "A Criança

Em conflito Com a Lei”, Maputo, 2003. 